\title{
Ineffective Hematopoiesis
}

National Cancer Institute

\section{Source}

National Cancer Institute. Ineffective Hematopoiesis. NCI Thesaurus. Code C36252.

A dysfunction in the production of blood cells, resulting in decreased numbers of mature, functioning blood cells of all lines in circulation. 